\title{
Study on the Significance of Cognitive Styles in Foreign Language Learning and Teaching
}

\author{
Yuan Yunbo \\ College of Management, Changchun University of Chinese Medicine, Changchun, China \\ yuan_yyb@163.com
}

Keywords: cognitive style; field independence(FI); field dependence(FD); Second language acquisition(SLA)

\begin{abstract}
The cognitive style of field independence (FI), as well as field dependence (FD), is one of the factors that influence learners' second language acquisition(SLA). In foreign language teaching, teachers should pay special attention to students' differences in styles, and adjust teaching strategies according to their learning characteristics, so as to maximize their potential. This paper starts from literature reviews of cognitive style at home and abroad, and then expands the research design including research subjects, research instruments, research questions, research results and research implications. The importance of paying attention to the students' different cognitive styles in foreign language teaching is emphasized in the part of conclusion.
\end{abstract}

\section{Introduction}

Contemporary college students have distinct personality characteristics which affect their English acquisition. Evidently, students' non-intelligent factors can't be ignored in English teaching. Therefore, to study on college students' development by means of classified English teaching is creative and forward-looking. Since the 60s of last century, the focus on English language teaching in the United States and other countries has began to shift, and gradually English teaching has taken students as the center of the teaching activities. Accordingly, researches have been turned to individual differences and the learning process to emphasize personality characteristics of learners. H.A.Witkin, American psychologist, first put forward the concept of cognitive style including Field Dependence and Field Independence in the 1940s, which has made educational psychologists and linguistics come to realize that knowing and distinguishing the different cognitive styles of learners functions significantly when tailoring students learning materials and helping them to choose learning strategies. The "field", from the perspective of Witkin et al., refers to people's perception or awareness along a continuum where there are two opposite sides identified as FD and FI, which has successfully predicted academic performance in a series of corresponding studies. The cognitive style receiving the most attention in the SLA started with Naiman et al., who did find a link between the cognitive style and second language achievement. H. D. Brown (2002) presents that FI is the ability enabling people to beware of the specific and relevant factors, thus perceiving the internal and external connections existed in a certain situation. It is generally believed that FI learners are more likely to be self-regulated and self-controlled in the process of preparation and operation, On the contrary, FD learners are considered to be more confident and cooperative in the specific settings related to much communication and cooperation(Yuan Yunbo, 2011).

Based on the concept of cognitive style proposed by Witkin, many Chinese educators have conducted application studies of FD/FI from the perspective of education. Li Zhe(2000) realized that individual differences help teachers to know better students, thus applying the most appreciate teaching methods and setting up the most suitable learning material to learners. Yuan Qian(2012) studied the relativity of the cognitive style and learning strategies, believing that learners' cognitive styles influence the selection and the use of learning strategies to some extent. But until now, most of the twenty-year studies of cognitive styles still have remained in the aspect of theory rather than specific application in a large scale. Besides, that most of the studies focus on general knowledge 
learners makes it distinctive to study the relativity between cognitive styles and language learning of SLA learners'. It may be greatly helpful for students with different styles to adopt the corresponding strategies. Meanwhile, it is imperative for teachers to put forward the concept of "classified teaching" and explore the suitable teaching mode for English class in the SLA field. This paper focuses on the differences between EFL (English as a Foreign Language) learners and studies on the significance of cognitive styles in foreign language learning and teaching.

\section{Research Design}

\subsection{Research Subjects}

The participants in the research are the sophomores from Changchun University of Chinese Medicine among whom there are 50 students from Chinese Medicine Major and 50 ones from the Department of Clinical Medicine, and among whom there are 40 students of the Liberal Arts and 60 Science students.

\subsection{Instruments}

\subsubsection{Questionnaire}

The first instrument involved is the questionnaire designed with 20 questions to practically judge the participants' cognitive style by evaluating their degree of Independence and Dependence tendency. The students are expected to choose "Agree" or "Disagree" conforming to their first reaction. One point will be added to the final score if the participant chooses" AGGRE " with the specific item and zero will be given if "DISAGREE" is chosen. After adding up all the items, subjects can find the corresponding styles from the score list.

\subsubsection{The Group Embedded Figures Test}

The cognitive style test used is a perceptual one in which the subjects are required to find out and depict a specified simple figure hidden in a more complex one, and the score reflects the ability to overcome hidden graphics. Participants, who can find out the simple figure rapidly and meanwhile score above the average, are considered to have an independent personality, and those who identify graphics hard and score below the average are regarded as the Field dependent people.

\subsection{Research Questions}

Since the study is a practical application research with exploratory nature, we propose the assumption that there is closely relationship between cognitive styles and foreign language learning, and appropriate learning strategies adopted can help to improve learning efficiency.

There is no denying that differences exist in cognitive styles between FI and FD in foreign language learning. How FD/FI relates to language learning and how to connect students' characteristics with the cognitive style theory and how to find a suitable teaching mode for personality development of SLA students are the key issues.

\section{Research Results}

The conclusion comes from the analysis of the test results and observation on the participants' classroom performance in the past three months. The differences between FI and FD in English learning are shown in the following aspects.

\subsection{On the Choice of Reading Materials}

In the selection of foreign language articles, field-dependent learners prefer to read humanistic and social articles in groups, while field-independent learners prefer to read natural science articles independently. Specifically, both field-dependent and field-independent participants in TCM major tend to hook their concept of TCM to English learning. They try to borrow the ideas and methods of Chinese medicine to diagnose and treat the symptom inspired by the teacher. For instance, Traditional Chinese Medicine holds that the treatment of diseases must be based on the root of the cause, and the ideal curative effect can only be achieved by finding the internal root 
cause of the disease and considering it from the local to the whole in the course of treatment. Feeling the pulse is one of the necessary diagnostic steps through which the TCM participants find that their problem hindering progress in spoken English lies in the neglect of English pronunciation. Most of the students who are weak in speaking can't pronounce words correctly, let alone complete sentences and texts. It is difficult for such students to get a sense of acquisition from speaking English, thus losing their interest in English learning. Comparatively, the participants in Clinical Major don't connect any specific concept related to Medicine with their English learning.

\subsection{On the Degree to Which the Structure of the Article is Grasped}

From the degree to which the participants understand the structure of the article, it is found that field-independent learners always stand in a relatively high position to achieve the overall grasp of the structure of the article, and that they can grasp the internal relations of the significant information. By contrast, the field-dependent learners are better at grasping the details of content and describing the partial and minor items of the article. Field-dependent learners are accustomed to using their own comprehensive thinking to understand and grasp the structure of the article by reading each word and sentence in the article. They read very carefully, and if there is a place that is not seriously read, they will feel that the whole article is not coherent. Of course, the inevitable consequence is that their reading speed is slow. Compared with field-dependent learners, although they improve their reading speed, field-independent learners lose some learning opportunities because of their lack of a good grasp of the article details. But one thing they do better than field-dependent learners is their analytical ability, especially for field-independent learners in Clinical Major who tend to find out links quickly among paragraphs by keys words.

\subsection{On the Response to the Influence of the External Environment}

In terms of the degree to which external influence of the environment is exerted, the field-independent learner is more able to firm his own position, eliminate the influence and interference of the outside world, and concentrate his mind on foreign language learning. While the field-dependent learner is more sensitive, expects more hints from the outside world, and also pays more attention to capturing information from books and teachers.

\section{Research Implications}

\subsection{Identify the Cognitive Styles of Students.}

Students with different cognitive styles should be identified. Assessing students' cognitive styles is important for both teachers and students in that learners with different cognitive styles have their own learning habits and characteristics. In the process of foreign language teaching, teachers should pay attention to identifying each student's learning style and grasping each student's learning characteristics so that the potentialities of students can be exploited to the maximum . Different teaching strategies should be adopted according to student differences. Modern teaching theory emphasizes not only the common progress of students but also the development of students' individuality. The characteristics of field independence make people have cognitive reconstruction ability, and field dependence makes people sociable, but the both promote foreign language learning in different ways. There is no doubt that learners bring many of their personal characteristics into the learning process, which not only affects their way of learning, but also affects their learning outcomes. For instance, field-independent learners with strong analytical skills are able to show their talents by analyzing the language material. In addition, they are good at using strategies to analyze inferential language information and create frameworks for language input and output, and thus they can use metacognitive strategies to fully anticipate the learning process, have the ability to monitor errors, and finally complete the construction of reflection, evaluation, error correction and etc. Under the influence of traditional learning culture, cognitive styles do not arouse enough attention from teachers who ignore the specific characteristics of students' learning modes in the actual teaching process, leading to the consequence in which students' potential advantages are not 
fully exploited.

There are many factors contributing to learning performance among which learner's learning styles and teacher's teaching style are equally important. What language teachers should do is to help learners learn more effectively and to support and encourage their individual control and self-learning. Therefore, if great importance is attached to the process of SLA teaching and learning, both field-dependent and field-independent learners can develop themselves in an efficient way.

\subsection{Apply Corresponding Strategies to Teaching.}

With the guidance of constructivism, corresponding teaching strategies should be put forward on the basis of different cognitive styles. Teachers, aware of teaching strategies, should consciously adjust their teaching methods to suit the cognitive style of most students, and pay attention to individual differences at the same time, thus cultivating students with different cognitive styles to properly implement their learning strategies. Respect for students' learning style is a teaching concept worthy of attention. On the premise of students' cognition, combining with teaching tasks, teachers should focus on cultivating students' interest, correcting their learning attitude, and encouraging students to establish their own knowledge structure independently. While taking advantage of students' individual differences, teachers should try to enrich students' learning experience so that each student can learn to reflect on and summarize what has been acquired in the study. Modern teaching theory advocates student-centered teaching mode. Therefore, teachers should perfect teaching strategies on the basis of taking into account two different cognitive styles in SLA teaching. In the process of perfecting teaching strategy, we should pay attention to the following points.

Firstly, due to the diversity of foreign language proficiency, students should be allowed to choose different levels of content and adopt different learning methods to complete the learning tasks. For example, field-independent learners, having less active contact with teachers apart from necessary class interaction, like to study alone and tend to be attracted more by competition in their study, and what they gain from competition is sure to motivate them effectively.

Secondly, teachers should pay attention to the relationship among students, teachers, knowledge and learning environment. Students with FI always star in the process of self-learning but ignore the interaction with class peers. So the teacher shouldn't forget to encourage such students to integrate themselves into the teaching activities created by both the teacher and the students.

Thirdly, in the relationship with teachers, field-dependent students tend to pay more attention to teachers, unlike field-independent learners who always build a more formal and serious relationship with teachers. In such case, teachers should pay more enthusiasm to establishing a closer and more reliable relationship with field-independent learners.

\subsection{Give full play to the advantages of cooperative Learning.}

Although the two different cognitive styles have disadvantages, they also have their own advantages. In foreign language teaching, teachers should try their best to bring the advantages of the two cognitive styles into full play. Cooperative learning is one of the best ways to fully mobilize the students' Learning Initiative and enthusiasm of the two learning styles. Merits of cooperative learning are typically demonstrated in the followings.

Firstly, ideas can be supplemented in the process of cooperative learning in which ideas collide, exchange, and inspire to create new ideas. Especially for field-dependent students, they get a sense of satisfaction and a sense of belonging in cooperation which greatly counts. Field-independent students can also give play to the advantages of speculation and leadership.

Secondly, cooperation helps to improving the thinking system through the debate and reflection. Cognitive styles shape one's thinking pattern. Think out of the box, you might discover something new. Cooperation helps both styles to make a breakthrough on stereotypes and improve the mode of thinking

Thirdly, improving interpersonal skills in cooperation is an appealing factor for students involved. Field-dependent learners are more willing to study together with others, and caring more 
about opinions of peers. For such students, learning in a group can be a chance to improve the performance with the reason that they want to be the focus of praise from both the teacher and classmates.

\subsection{Take Advantage of Multimedia.}

With the development of information technology, the application of multimedia technology in classroom is widely recommended. Teachers use video, audio and other multimedia resources to help students understand learning materials, arouse their interest and get students warmed up. Students are encouraged to use the network to collect more information to conduct the autonomous learning in which FI students may get more by means of self-regulation. Multiple utilization of technology helps to develop self-study ability of students. Compared to FI students, FD ones are more likely to study with the guidance from teachers, so they may be less efficient after class. Micro class, MOOC and other online resources are created to deal with the deficiency. For one thing, the sharing of network knowledge will make students expand their knowledge and break the thinking mode. For another, online courses are indispensable supplements to FD students. Teachers should give reasonable advice and guidance for students with different cognitive styles, so as to avoid confusion caused by the huge information network. Autonomous learning model based on computer network is a new foreign language teaching mode in which teachers make full use of network resources to provide learners with a large amount of real language materials and Learners construct their knowledge at the same time in a variety of ways provided online so that they can respond appropriately to challenges.

\section{Conclusion}

Since students show two different cognitive approaches to foreign language learning, teachers should pay attention to the differences between the two cognitive styles in order to get the teaching methods recognized by most students. By combining the characteristics of students and teaching tasks, teachers should develop a unique and practical teaching strategy to maximize students' potential and achieve the desired teaching effect.

Fund: Hundred Teachers Program of Changchun University of Chinese Medicine

\section{References}

[1] Yuan Yunbo. Study on Foreign Language Learning Strategies and Cognitive Styles of Field-dependence and Field-independence[D].Changchun, Changchun University of Technology. 2011: 8

[2] Li Zhe. Differences in Learners' Cognitive Styles and Foreign language Teaching[J]. Foreign Language Education,2000,03:61-64

[3] Yuan Qian. An empirical study of the relationship between Cognitive style and Learning Strategies[J]. Educational Research and Experiment, 2012,02:93-96 